\title{
On the impact of organizational structure on organizational efficiency in industrial units: industrial units of Kerman and Hormozgan Provinces
}

\author{
Kamran Ghorbannejad Estalaki ${ }^{1}$
}

1 Department of Management, Baft Higher Education Center, Shahid Bahonar University of Kerman, Kerman, Iran. Email: kghorbannejad@uk.ac.ir

\begin{abstract}
The present study using applicable attitude have investigated relationship between organizational structure and efficiency among employed personnel in industrial units of Kerman and Hormozgan provinces. For data collection a standardized Robbins's (1998) questionnaire to assess the organizational structure and Hersey and Goldsmith's standard questionnaire is used to assess aspects of organizational productivity. Sample of the study includes Personnel employed in industrial units of Kerman and Hormozgan provinces that using on random sampling and Morgan table, sample size of 384 is considered gathered data are analyzed using correlation coefficient and linear regression. The components of the model and the type of relationship that they have is identified and reported. In order to do analyses Excel and SPSS15 soft wares are used. The findings showed that there is significant relationship between efficiency in industrial units with organizational structure and its components including complexity, formality and concentration.
\end{abstract}

Keywords: organizational structure, organizational efficiency, industrial units, linear regression

\section{INTRODUCTION}

The success or failure of any organization depends on amount of people efforts in the organization and especially organizational structure in order to achieve aims of firm that is possible by efficient use of hardware and software resources (BRIDGES; BRIDGES, 2017). In this regard ability of the management to motivate and create the desire to work hard on employees has a major role, so management structure of organization is mentioned as a vital link between management and staff. Because of the organizing principles policies implementation, management structure could be useful in use of investments, efficient technology, advanced methods of work, the methods of motivating human resources and so on in order to improving productivity in organizations (BRANDT; AGRAWAL, 2016).
Organizational structure is considered as formal and rational distribution of jobs, responsibilities, powers and the way of coordination and communication in order to achieve the main objectives of and one of the first institutions that arise in any organization in its inception (RAMADANI, 1994). The first step in order to increase productivity, is to identify its affecting factors. The result of studies have shown that organizational structure is one of the most important factors affecting organizational efficiency both now and in the past. Today we live in the age of organization and the importance of organization and organizing to manage affairs better has become an issue. If organizations be consistent with the tasks and goals and be governed based on the scientific principles, their efficiency and productivity would increase and they would were successful in executing orders and 
achieve organizational goals (SCOTT, 2016). In contrary if organizing and structure that is its harvest don't be align with tasks, goals, combining human resources and environmental requirements and ... operations will face difficulties and will force managers to spend their time on solving problem which are arisen from incorrect structure. Nowadays efficiency is more than an economical gauge or index, but as a holistic approach, is a system-oriented culture and attitude, and an overview of all components. So that could have mutual effect on the economic, social and cultural aspects of countries, organizations or even individuals (MOSHABAKKI, 1996).

Nowadays increasing productivity in organizations is one of the main concern of executives and decision-makers, in a way that most of countries based their major development programs on increasing productivity. So that during the last fifteen years, increasing productivity in the world, became 45 times higher. Productivity on the one hand, is factor of improving living standards and reducing inflation and on the other hand, causes change in relative prices, an increase in actual production and the efficient allocation of resources. In a word, economic growth depends on productivity growth (BORDBAR et al., 2008). Organizations are set of people who have gathered for the realization of a goal. In order to gain the goals people should be organized in the best possible structure. Decisions about the structure are of the most basic strategic decisions. Structure of an organization can create or destroy it (OLIVE et al., 2008).

Efficiency as one of the management performance indicators is success indication of an organization. The efficiency is influenced by various factors that in this respect, management structure have the fundamental role (KADKHODAll, 1997). With a view to efficiency as a performance index and identifying affecting factors and creating dynamics and favorable changes in them, ability to obtain acceptable and high rate of efficiency is available. With careful consideration of the above mentioned in industrial companies the impact of organizational structure and productivity could be investigated in order to be an epigraph for industrial units and organizations (PRADHAN; ROUTROY, 2016). Movement and economic growth, are a sign of efficiency and level of productivity yield the size of the growth and development of the economy. Productivity is a measure for evaluating the performance of the organization, or in other words, evaluation criteria of the organization's efforts that this criterion is the most important indicator to indicate the success or failure of the organization (MCCOMBIE; THIRLWALL, 2016). Productivity is a simple concept: the relationship between an organization and institutions required output. By dividing outputs to inputs, the productivity can be determined. Also with improving this ratio, the amount of efficiency could be added means that with a certain level of inputs, more or better outputs can be achieved. Briefly efficiency can be named productivity plus effectiveness (MANAGEMENT EFFICIENCY DIRECTORY, 1996). Management structure simplifies balanced distribution activities and their financial and economic impacts and through productivity increase level of efficiency. Based on the above discussion, the main objective of this study is to investigate impact of organizational structure on efficiency in industrial units. 


\section{THEORETICAL FOUNDATIONS}

Management structure of organization is mentioned as a vital link between management and staff. Because of the organizing principles policies implementation, management structure could be useful in use of investments, efficient technology, advanced methods of work, the methods of motivating human resources and so on in order to improving productivity in organizations (MIRSEPASI, 1995). Efficiency as one of the management performance indicators is success indication of an organization. The efficiency is influenced by various factors that in this respect, management structure have the fundamental role. In this respect the following factors, which are effective in detailed changes of effective productivity can be named. efficient use of human resources, scientific management techniques, appropriate structure and stability of regulations, fill the information vacuum, power regulatory aspects, motivational incentives, efficiency (KADKHODAll, 1997). Concept of efficiency is simple. Inputs or charges; the order of the term is all needed resources to produce goods or services. In the efficiency discussion inputs or sources are manpower, machinery, raw materials, land, information, time, and energy... (MIRSEPA-SI, 1995). Outputs; the meaning of this term is the result of production system Operations. The final output can be in the form of goods or services. Performance is defined as ratio of achieved actual returns to set the standard output (expected), indeed it is the ration of work that is done to the work that is expected to be done. Effectiveness is the degree of achieving to the goals set, in other words effectiveness shows that to what extent desired results have been achieved through the efforts. Indeed effectiveness is related to efficiency and providing human satisfaction of made efforts and has qualitative aspect (ABTAHI; KAZEMI, 1996).

Naziri (2012) in his research concluded that there is a weak inverse significant relationship between organizational structure and organizational entrepreneurship. Among the indicators of organizational structure, only recognition index is associated with organizational entrepreneurship and there is no significant relation between the other indices (complexity and concentration) with organizational entrepreneurship. Shoa'i (2011) in his research concluded that there is association between organizational structure (formality), organizational structure (complexity), organizational structure (focus) and knowledge creation. Abdekhoda had showed that the organizational structure has a significant effect on productivity. Whatever structure be more concentrated, formal and complex productivity is lower. Khalifasoltani (2008) suggests that there is meaningful relationship between structure, complexity, formalization, concentration and entrepreneurship, and also negative significant relationship between age, work experience and entrepreneurship but there is no relationship between level of education and organizational entrepreneurship. Abutorabi (2008) observed that low levels of formality and concentration and a high level of communication flow are associated with high levels of production and knowledge transfer and these are crucial for knowledge management success. Asgari (2004) concluded that there is association between structures, reducing the recognition, concentration, facilitating the flow of communication with the increase in the creation and transfer of 
knowledge. In other cases it is necessary to implement knowledge management to organization have good ICT infrastructure, employees have the necessary technology training and organization has culture of knowledge sharing and continuous learning. Samadi (2003) showed that labor productivity has positive and unemployment rate has negative impact on wages of labor and he believes that there is one-sided causal relationship between wages of labor with productivity and this is true efficiency wage theory. Rezazadeh (2002) showed that there is relation between complexity, formalization and concentration in organizational decision making and organizational entrepreneurship. Eghbali (2000) concluded that there is significant association between productivity in crescent and participatory space existence, using the Comments staff in goal setting, use the Comments staff in monitoring the implementation of targets, using employee feedback to improve methods and system, the implementation of cooperative system. There is no significant association between productivity increment with commitment and responsibility. Davoodi (2000) suggests that there is no relation between organizational complexity Football Association and decision-making speed and information flow. There is relationship between Football Association organizational recognition and the speed of decision-making, information flow.

Slaver et al. (2011) showed that competition policy has a positive impact on organizational structure and its function. While the Organizational focuses has negative impact on organizational structure and its performance. The organizational structure has no direct impact on performance, but has indirect impact on competitive policies.
Berly et al. (2009) concluded that informal relations play an important role in defining and understanding the internal structure of organizational activities. Informal relations, trust-based relationships, comprehensive external relations and pervasive emotional relationships are actual energy infrastructure of organizations. Evolution of structure shows that in a dynamic environment organizational structure should be open, emotion-centric, interaction-driven, flexible and self-centered. Williams and Bolonz (2009) showed that deconcentrating improves organization performance but cannot compensate differences and organizational complexity and knowledge. This means in places where there is need for professional skills and complexity cannot be said that deconcentrating can completely solve problems. Bozbora (2007) says it is good enough to exist decentralized structure to foster an environment in which employees can participate in the process of knowledge creation. Cathrin et al. (2005) provided organizational structure based on participation in the chart that mechanical dimensions of the organizational structure reduced and organic structure increased. Linderz et al. (2005) concluded that there is association between the levels of concentration and creativity managers. In organizational positions with low levels of concentration, persons provide more comments and further information and exchange thereby create creative perspectives. As well as facilitate the exchange of information and interaction between people lead to producing more meaningful information in order to effectively deal with dynamic environments. Instead, high levels of concentration lead to develop ideas and disruptive protest and hinder the develop- 
ment of new ideas. Boner et al. (2003) suggest that there is meaningful relationship between official control and employee creativity. As low degree of official control is essential for efficient management and official control of inappropriate or team creativity in organizations too can be cut. Santis et al. (2003) concluded that there is relationship between organizational structure and the amount of creativity and innovation in organizations. Flexible structure not only leads to the development and progress in the implementation of new ideas but the novelty of this structure is much more than rigid structure. Hunter (2002) says organizational units with less complexity which their managers have used the style of participative management system had increased organizations entrepreneurship percentage. Whatever the organizational hierarchy is less vertical and horizontal linkages between employees be higher, as well provide the right atmosphere for entrepreneurial initiatives. Marshal et al. (2000) have studied "regarding the organizational structure and sense of justice". In this study the relationship between the dimensions of organizational structure (complexity, formalization, concentration) and their size with a sense of justice are examined. Mintzburg (1972) have defined organizational structure as: The structure organization as a general sum can recognize methods which determines duty of people in separate sectors and then provide their coordination. Organizations have different types of structure that are using according to the requirements and conditions of organization. In a general classification organizational structure divided in two types of mechanical and organic structure. Mechanical structure in stable and predictable environment and organic structure in turbulent environments and significant changes are useful (GRESO; DARZEIN, 2007). The mechanical structure of the organization are recognized by details such as high formalization, concentration and planned behavior in the form of regulations (MEYM et al., 2010). On the other hand the organic structure is flexible and is known by details such as decentralized authority, laws and regulations less, informal communications network (MARS; SIMON, 2009). According to various definitions on aspects of structure, a definitive diagnosis a set of organizational dimensions without a framework and purpose is difficult (MORTON; HO, 2008). In this study Robinz's (1998) study about dimensions of structure is index of organizational structure.

The three components of complexity, formalization and concentration are as follows:

A) Complexity: according to Daft (2006) complexity is number of administrative levels in the organization. In general complexity is said to the rate of job titles (distribution of jobs within the organization), the number of hierarchy and levels of management, education and geographical distribution of each organization units. Complexity, includes vertical and geographic complexity (GERSU; DARZIN, 2007). Geographical complexity considers separation between the units based on geographic location. Vertical complexity considers number of organizational levels, management layers in the organization, complexity of horizontal resolution and the number of jobs both groups and peers at the same organizational level (MARS; SIMON, 2005).

B) Formalization: formalization is the amount that organizations use to describe 
the behavior of rules and procedures (LIAO et al., 2010). In general formalization is compiling and publishing the rules, regulations, instructions, regulations, and job descriptions are taken into consideration and that the organization is registered (GERSU; DARZIN, 2007). Formalization has two parts: The first part is the written laws and regulations of the organization and the second part is the degree to which these laws and regulations and compliance guidelines, implemented and controlled (MARS; SIMON, 2005).

C) Concentration: The third dimension of organizational structure is concentration. Most theorists agree that concentration indicates decision-making power at higher levels of management in the organization (LIAO et al., 2010). More concentration cause uniformity of policy and reducing errors that cause to risk by employees who have less information or skills (KATSICA et al., 2011).

According mentioned discussion model of the research is pictured as bellow:

Figure 1: The research mode-originated from Robbins's organizational structure and Hersey and Goldsmith's efficiency model

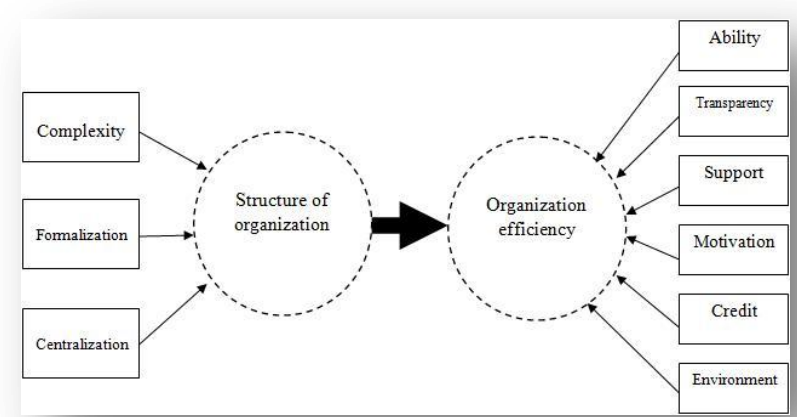

Research Hypotheses

Main hypothesis

Organizational structure in industrial units has significant positive impact on effi- ciency.

Sub-hypotheses

Complexity of organizational structure in industrial units has significant positive impact on efficiency.

Formality of organizational structure in industrial units has significant positive impact on efficiency.

Concentration of organizational structure in industrial units has significant positive impact on efficiency.

\section{METHODOLOGY}

The present study from the view point of aim is applicable type and from the view point of data gathering is field-descriptive type in a way that to confirm hypotheses, survey from engaged people (employed personnel in industrial units of Kerman and Hormozgan provinces) is done. Moreover based on the type of data collection which is quantitive there were questionnaires that distributed among workers in in industrial units. Needed information to do the study is gather through two ways: 1.library method: in this method to collect related information to topic literature and previous studies, books, articles and data sources available in internet are used. 2. Field methods: for data collection a standardized Robbins's (1998) questionnaire to assess the organizational structure and Hersey and Goldsmith's standard questionnaire is used to assess aspects of organizational productivity. Sample of the study includes Personnel employed in industrial units of Kerman and Hormozgan provinces that their population are more than 100 thousand people, so using based on random sampling and Morgan table, sample size of 384 is considered. After completing the questionnaire 
and collect the required information from the field territory, using correlation coefficient and linear regression, the components of the model and the type of relationship that they have is identified and reported. In order to do analyses Excel and SPSS15 soft wares are used.

\section{RESULTS}

According to the findings $3.3 \%$ of respondents were under 35 years old, $25 \%$ were between 36 to $40,25 \%$ between 41 to 45 , 31.1\% between 46 to 50, 9.4\% had more than 50 years old and $6.1 \%$ have not responded to this question. Also 33.3\% were women and $60.6 \%$ were men and $6.1 \%$ have not responded to this question. $31.4 \%$ of respondents had bachelor's degree, $65.5 \%$ had master degree and 3.1\% have not responded to this question. Finally $3.3 \%$ of respondents had work experience of less than 10 years, $25 \%$ between 10 to $15,18.6 \%$ between 16 to $20,25 \%$ between 21 to $25,21.9 \%$ more than 25 years and $6.1 \%$ have not responded to this question.

According to the descriptive variables (mean, standard deviation, maximum and minimum scores) were calculated for variables, are represented in Table 1.

Table 1. Descriptive information of variables $(n=384)$

\begin{tabular}{|l|c|c|c|c|}
\hline Variable & Average & $\begin{array}{r}\text { Standard } \\
\text { deviation }\end{array}$ & $\begin{array}{r}\text { Maximum } \\
\text { scores }\end{array}$ & $\begin{array}{c}\text { Minimum } \\
\text { scores }\end{array}$ \\
\hline Complexity & 3.026 & 0.461 & 5 & 1 \\
\hline Formalization & 3.061 & 0.612 & 5 & 1 \\
\hline Concentration & 3.000 & 0.481 & 5 & 1 \\
\hline Ability & 2.972 & 0.339 & 5 & 1 \\
\hline Transparency & 3.152 & 0.358 & 5 & 1 \\
\hline Support & 3.169 & 0.423 & 5 & 1 \\
\hline Motivation & 3.002 & 0.643 & 5 & 1 \\
\hline Credit & 3.161 & 0.521 & 5 & 1 \\
\hline Environment & 2.971 & 0.364 & 5 & 1 \\
\hline $\begin{array}{l}\text { Organization } \\
\text { efficiency }\end{array}$ & 3.164 & 0.427 & 5 & 1 \\
\hline
\end{tabular}

Estação Científica (UNIFAP)

ISSN 2179-1902

\begin{tabular}{|l|l|l|l|l|}
\hline $\begin{array}{l}\text { Organizational } \\
\text { Structure }\end{array}$ & 2.994 & 0.313 & 5 & 1 \\
\hline
\end{tabular}

\subsection{Normality test of variables}

Normality test results of the data is summarized in Table 2. According to the table Kolmogorov-Smirnov test values and significance level for variables which cover hypotheses of the study are represented.

Table 2: Normality test results of studied variables $(n=384)$

\begin{tabular}{|l|c|c|c|}
\hline Variable & $\begin{array}{c}\text { Kolmogorov- } \\
\text { Smirnov test }\end{array}$ & $\begin{array}{c}\text { Significance } \\
\text { level }\end{array}$ & Result \\
\hline Complexity & 0.548 & 0.948 & Normal \\
\hline Formalization & 0.381 & 0.846 & Normal \\
\hline Concentration & 0.192 & 0.919 & Normal \\
\hline Ability & 0.254 & 0.742 & Normal \\
\hline Transparency & 0.169 & 0.834 & Normal \\
\hline Support & 0.162 & 0.984 & Normal \\
\hline Motivation & 0.261 & 0.768 & Normal \\
\hline Credit & 0.194 & 0.816 & Normal \\
\hline Environment & 0.091 & 0.946 & Normal \\
\hline $\begin{array}{l}\text { Organization } \\
\text { efficiency }\end{array}$ & 0.094 & 0.986 & Normal \\
\hline $\begin{array}{l}\text { Organizational } \\
\text { Structure }\end{array}$ & 0.084 & 0.852 & Normal \\
\hline
\end{tabular}

As can be seen the significant level of research variables all are more than 0.05 , so the null hypothesis is accepted. As a result, data on the variables, are normal. Therefore in this study, we are allowed to use parametric tests.

\subsection{Calculating the correlation coefficient}

Using correlation test an initial communication can be established to investigate the relationship between constructive factors. This type of communication or correspondence between constructive factors are used to see twofold correlation coefficient among constructive factors. In Table 3, correlation matrix, correlation coefficients of total points for each component is represented. 
Table 3: correlation between the underlying constituents of hypotheses

\begin{tabular}{|l|c|c|c|c|c|c|c|c|c|c|c|}
\hline Variable & Com. & Form. & Con. & $\begin{array}{c}\text { Abi- } \\
\text { lity }\end{array}$ & Trans. & $\begin{array}{c}\text { Sup. } \\
\text { Mo- }\end{array}$ & $\begin{array}{c}\text { Cre- } \\
\text { tiv. } \\
\text { dit }\end{array}$ & $\begin{array}{c}\text { Env. } \\
\text { O-ef }\end{array}$ & $\begin{array}{c}\text { O-Str } \\
\text { fici } \\
\text { en } \\
\text { cy }\end{array}$ & $\begin{array}{c}\text { uctu } \\
\text { re }\end{array}$ \\
\hline Complexity & 0.548 & 1 & & & & & & & & & \\
\hline Formalization & 0.381 & 0.10 & 1 & & & & & & & & \\
\hline Concentration & 0.192 & 0.41 & 0.15 & 1 & & & & & & & \\
\hline Ability & 0.254 & 0.42 & 0.41 & 0.54 & 1 & & & & & & \\
\hline Transparency & 0.169 & 0.31 & 0.23 & 0.51 & 0.61 & 1 & & & & & \\
\hline Support & 0.162 & 0.40 & 0.45 & 0.60 & 0.61 & 0.46 & & & & & \\
\hline Motivation & 0.261 & 0.43 & 0.54 & 0.41 & 0.28 & 0.54 & 1 & & & & \\
\hline Credit & 0.194 & 0.40 & 0.59 & 0.30 & 0.33 & 0.51 & 0.46 & 1 & & & \\
\hline Environment & 0.091 & 0.21 & 0.37 & 0.32 & 0.55 & 0.28 & 0.59 & 0.69 & 1 & & \\
\hline $\begin{array}{l}\text { Organization } \\
\text { efficiency }\end{array}$ & 0.094 & 0.34 & 0.25 & 0.31 & 0.29 & 0.63 & 0.62 & 0.66 & 0.74 & 1 & \\
\hline $\begin{array}{l}\text { Organizationa } \\
\text { Structure }\end{array}$ & 0.084 & 0.62 & 0.63 & 0.58 & 0.65 & 1 & 0.68 & 0.69 & 0.67 & 0.69 & 1 \\
\hline
\end{tabular}

Correlation is significant at the 0.01 level.

4.3 Regression analysis: examine the relationship between organizational structure and efficiency

Multiple regression analysis using SPSS15 software is done in order to investigate the relationship between organizational structure and efficiency in the case of industrial units personnel. The independent variable is organizational structure, and the dependent variable is productivity. Tables 4, 5, 6 and 7 are representing analysis of organizational structure with efficiency relationship. The regression analysis also show that the relationship between organizational structure and efficiency with a statistical confidence level of $95 \%$ is verifiable $(P<0.05)$. Also adjusted $R^{2}$ is equal to 0.792 which confirms te relationship. The results would appear that efficiency in industrial units can be explained by the organizational structure. Thus the main hypothesis of this study is approved (Table 4).
Table 4: main hypothesis assessment

\begin{tabular}{|l|c|c|c|}
\hline \multicolumn{1}{|c|}{ Research hypothesis } & $\boldsymbol{\beta}$ & t-value & Result \\
\hline $\begin{array}{l}\text { Organizational structure in } \\
\text { industrial units has significant } \\
\text { positive impact on efficiency. }\end{array}$ & 0.462 & 7.841 & confirmed \\
\hline
\end{tabular}

Table 5: Regression analysis of organizational structure on efficiency

\begin{tabular}{|l|c|c|c|c|}
\hline $\begin{array}{l}\text { Independent } \\
\text { variables }\end{array}$ & $\boldsymbol{\beta}$ coefficient & $\begin{array}{c}\text { Standard } \\
\text { Error }\end{array}$ & t-value & $\mathbf{P}$ \\
\hline constant & & 0.223 & 2.926 & 0.004 \\
\hline $\begin{array}{l}\text { Organizational } \\
\text { structure }\end{array}$ & 0.462 & 0.063 & 7.841 & 0.000 \\
\hline
\end{tabular}

Table 6: Regression analysis II: ANOVA

\begin{tabular}{|c|c|c|c|}
\hline Model & $\begin{array}{c}\text { Durbin-Watson } \\
\text { statistic }\end{array}$ & $\mathbf{R}^{\mathbf{2}}$ & Adjusted $\mathbf{R}^{\mathbf{2}}$ \\
\hline 1 & 1.85 & 0.812 & 0.792 \\
\hline
\end{tabular}

Table 7: Regression analysis II: coefficients

\begin{tabular}{|c|c|c|c|c|c|c|}
\hline Model & $\begin{array}{c}\text { sum of } \\
\text { squares } \\
\text { (OLS) }\end{array}$ & df & $\begin{array}{c}\text { Mean } \\
\text { Square }\end{array}$ & F & Sig. \\
\hline 1 & Regression & 71.894 & 2 & 35.947 & 63.933 & \\
\hline & Residual & 200.728 & 357 & 0.562 & & \\
\hline
\end{tabular}

As stated Durbin-Watson statistic is equal to 1.85 which shows there is no significant error in correlations so we are allowed to use linear regression. $\mathrm{R}^{2}$ and adjusted $R^{2}$ statistics are respectively 0.812 and 0.792 that show the fitted repression model can explain $79 \%$ of efficiency behavior in industrial units as dependent variable. This result confirm the main hypothesis of the study.

\subsection{Regression: Testing the relationship between dimensions of organizational structure and efficiency}

By examine the theoretical foundations three dimensions of organizational structure are considered as: complexity, formality and concentration. The main objective of this research was to achieve a regression analysis of the relationship between Efficiency as the dependent variable and com- 
plexity, formality and concentration as independent variables. Obtained results are shown in table8. Adjusted $\mathrm{R}^{2}$ is 0.734 which shows being meaningfulness of the relation. Tables 8, 9 and 10 are representing regression analysis for the relationship.

Table 8: Regression analysis I: model summary

\begin{tabular}{|c|c|c|c|}
\hline Model & $\begin{array}{c}\text { Durbin-Watson } \\
\text { statistic }\end{array}$ & $\mathbf{R}^{2}$ & Adjusted $\mathbf{R}^{2}$ \\
\hline 2 & 1.93 & 0.751 & 0.734 \\
\hline
\end{tabular}

Table 9: Regression analysis I: ANOVA

\begin{tabular}{|c|c|c|c|c|c|c|}
\hline Model & $\begin{array}{c}\text { Sum of } \\
\text { squares } \\
\text { (OLS) }\end{array}$ & df & $\begin{array}{c}\text { Mean } \\
\text { Square }\end{array}$ & F & Sig. \\
\hline \multirow{2}{*}{1} & Regression & 326.207 & 3 & 107.734 & 86.732 & 0.000 \\
\cline { 2 - 7 } & Residual & 423.783 & 380 & 1.253 & & \\
\hline
\end{tabular}

Table 10: coefficients of regression

\begin{tabular}{|c|c|c|c|c|c|}
\hline \multirow[t]{3}{*}{ Constants } & \multicolumn{2}{|c|}{$\begin{array}{c}\text { Standardized } \\
\text { coefficient }\end{array}$} & \multirow{2}{*}{$\begin{array}{c}\text { Standar- } \\
\text { dized } \beta \\
\text { coeffici- } \\
\text { ent }\end{array}$} & \multirow[t]{2}{*}{$\mathbf{t}$} & \multirow[t]{2}{*}{ Sig. } \\
\hline & B & \begin{tabular}{|c|} 
Standard \\
Error
\end{tabular} & & & \\
\hline & -0.233 & 0.338 & & -0.585 & 0.514 \\
\hline Complexity & -0.967 & 0.089 & -0.227 & -5.234 & 0.000 \\
\hline Formalization & 0.932 & 0.535 & 0.084 & 3.563 & 0.001 \\
\hline Concentration & 0.956 & 0.064 & 0.267 & 4.679 & 0.000 \\
\hline
\end{tabular}

\subsection{The dependent variable: produtivity}

As stated Durbin-Watson statistic in Table 8 is equal to 1.93 which shows there is no significant error in correlations so we are allowed to use linear regression. $\mathrm{R}^{2}$ and adjusted $R^{2}$ statistics are respectively 0.751 and 0.734 that show the fitted regression model can explain $73 \%$ of efficiency behavior in industrial units as dependent variable. This result confirm sub-hypotheses of the study.
Table 11: summary of sub-hypotheses assessment

\begin{tabular}{|l|c|c|c|}
\hline \multicolumn{1}{|c|}{ Sub-hypotheses } & $\boldsymbol{\beta}$ & $\mathbf{t}$ & Result \\
\hline $\begin{array}{l}\text { Complexity of organizational } \\
\text { structure in industrial units has } \\
\text { significant positive impact on } \\
\text { efficiency. }\end{array}$ & 0.227 & 5.234 & confirmed \\
\hline $\begin{array}{l}\text { Formality of organizational } \\
\text { structure in industrial units has } \\
\text { significant positive impact on } \\
\text { efficiency. }\end{array}$ & 0.084 & 3.563 & confirmed \\
\hline $\begin{array}{l}\text { Concentration of organizational } \\
\text { structure in industrial units has } \\
\text { significant positive impact on } \\
\text { efficiency. }\end{array}$ & 0.267 & 4.679 & confirmed \\
\hline
\end{tabular}

\section{CONCLUSION}

In today's competitive world, efficiency as a philosophy and a attitude based on recovery strategy, forms main goal of any organization to form and can cover all sectors of the population activities such as chain.so that mission of managers and main objective of any organization managers is effective and efficient use of various resources such as labor, capital, materials, energy and information. This has caused in all countries Efficiency and correct and better use of total factors of production (both goods and services) become a national priority and all communities to believe that survival of any society is not possible without considering the efficiency issue. Our country is no exception and considering the issue of Efficiency has a significant role in its development.

The existence of a poor structure and poor working environment, improper relations of manager with staff result in work ethic and labor productivity got minimized. Although all the basic institutions for crop production are important, but that is only human power that has other inputs udder the control. So attract and recruit skilled and motivated strong human resource can use sophisticated technology, machinery, 
equipment and tools as well (TAHERI, 2011). Therefore appropriate organizational structure is essential in the management of these valuable resources. Through human resource management they can recruit and select human resources commensurate with the organization's future goals. Because success and failure in achieving organizational goals depends on find and select the committed and skilled manpower (ABTAHI, 2008). To understand the organization in terms of paving the way for increased labor productivity such aspects of the organization should be understood that are expressing special features of organizations. Structural aspects (complexity, formalization, concentration) describes the features within an organization. Findings show that among the components of the organizational structure, concentration component has the greatest impact on productivity, industrial organization. In this regard, it is suggested industrial organizations plan and implement strategies to strengthen organizational concentration. The findings also show that organizational complexity has negative and significant impact on organization efficiency. In this regard, it is suggested industrial organizations plan and implement strategies to reduce organizational complexity. Formalization component has small but significant and positive impact on the productivity of industrial organizations. The most important limitation of this study included the above mentioned provisions questionnaire and distribution of the population.

\section{REFERENCES}

ABTAHI, H. Human resource management, field management, Payame Noor publisher,
1999.

ABTAHI, H.; KAZEMI, B. Efficiency, Tehran, Institute for Trade Studies and Research, 2002.

ABOTORABI, M. Relationship between organizational structure and knowledge management of employees of South Khorasan physical education, physical education students of the fifth. Conference of Sports Science, Mazandaran University, 2008.

ASGARI, N. Investigate the relationship between structural factors (structure, culture, technology) Ministry of Labor and Social Affairs with knowledge management strategy. Master thesis, Tehran University, 2006.

SCHOOL EGHBALI. Investigate the relationship between cooperative systems by increasing efficiency. Master's thesis, 2002. BRIDGES, W.; BRIDGES, S. Managing transitions: Making the most of change. Da Capo Press, 2017.

BRANDT, J. S.; NOLTE, C.; AGRAWAL, A. Deforestation and timber production in Congo after implementation of sustainable forest management policy. Land Use Policy, n. 52, p. 15-22, 2016.

CHILD. J. Organization structure, environment, and performance: the role of strategic choice. Sociology, n. 6, p. 1-22, 2008.

DAVOODI, B. Organizational structure and provide optimal federation. Master's thesis, Tehran University, 2002.

GRESOV. C.; DRAZIN. R. Equifinality: functional equivalence in organization design. Academy of management review, n. 22, p. 403-428, 2007.

KADKHODAYI, $\mathrm{H}$. Identifying reasons for low productivity. Journal of Public Administration, n. 33 and 34, 1997.

KATSIKEA, E; THEODOSIOU, M; PERDIKIS, N; KEHAGIAS, J. The effects of organizational 
structure and job characteristics on export sales managers' job satisfaction and organizational commitment. Journal of World Business, n. 46, p. 221-233, 2011.

LIAO CH.; SHU-HUI CH.; PUI-LAI T. How knowledge management mediates the relationship between environment and organizational structure. European Management Journal, 2010.

MIHM, J.; LOCH, C. H.; WILKINSON, D.; HUBERMAN, B. A. Hierarchical structure and search in complex organizations. Management Science, v. 56 n. 5, p. 831-848, 2010.

MARCH, J.; SIMON, H, Organizations, Blackwell. Cambridge, MA, 195-324, 2009.

MORTON A.N; HU, Q. Implications of the fit between organizational structure and ERP: A structural contingency theory perspective. International Journal of Information Management, n. 28, p. 391-402, 2008. MIRSEPASI, N. Human resource management and labor relations. Publications pearls, 1995.

MOSHABAKKI, A. Management and efficiency: The Elixir of work and production, 1995.

MCCOMBIE, J.; THIRLWALL, A. P. Economic growth and the balance-of-payments constraint. Springer, 2016.

NAZIRI, S. Organizational structure with business organizations and professional technical. Tabriz master's thesis, University of Tabriz, 2012.

OMIDI, A. The relationship between organizational structure and organizational creativity of Physical Education Organization. Master's thesis, Tehran University, 2007.

PRADHAN, S. K.; ROUTROY, S. Supply management integration model for Indian manufacturing industries. International Journal of Operations \& Production Management, v. 36, i. 7, 781-802, 2016.

ROBBINS, S. P. Organization theory New York. Prentice Hall, 1998.

RAMADANI, B. Develop organizational structures. Strategy Journal, Issue 36, 1994. SCOTT, W. R. Organizational sociology. Routledge, 2016.

SHOA'I, J. Examine the relationships between organizational structure (structure and culture) with technical and professional knowledge management strategy Tabriz. Master Thesis, University of Tabriz, 2011.

SAMADI. The relationship between wages and labor productivity in large industrial workshops, lasting a master. 2005.

TAHERI, S. Efficiency and analysis in organizations. Nineteenth printing, Hastan publishing, 2012.

WILLEM, A; BUELENS, M. Knowledge sharing in inter-unit cooperative episodes: The impact of organizational structure dimensions. International Journal of Information Management, n. 29, p. 151-160, 2009.

\section{(c) (1) \\ License information: This is an open- access article distributed under the terms of the Creative Commons Attribution License, which permits unrestricted use, distribution, and reproduction in any medium, pro- vided the original work is properly cited.}

Article received on September 06, 2017.

Evaluated June 06, 2017.

Accepted on December 04, 2017.

Published on December 19, 2017.

How cite this article (ABNT):

ESTALAKI, Kamran Ghorbannejad. On the impact of organizational structure on organizational efficiency in industrial units: industrial units of Kerman and Hormozgan Provinces. Estação Científica (UNIFAP), Macapá, v. 7, n. 3, p. 95-105, set./dez. 2017. 